Nr. 7/2009 (EN)

\title{
Why Don't They Answer? \\ - Unit Non-Response in the IAB Establishment Panel
}

Florian Janik and Susanne Kohaut 


\section{Contents}

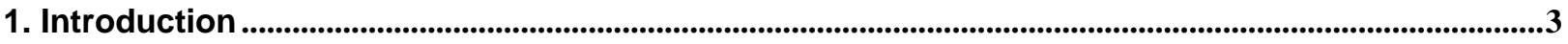

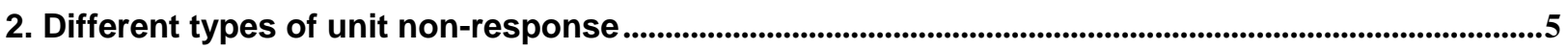

3. Explaining the decision to participate in establishment surveys .........................................................

3.1 A conceptual framework

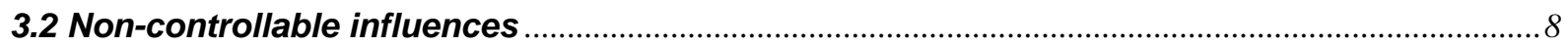

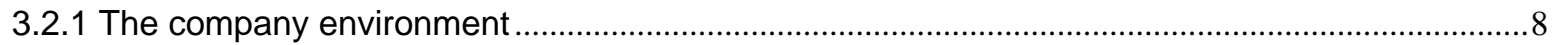

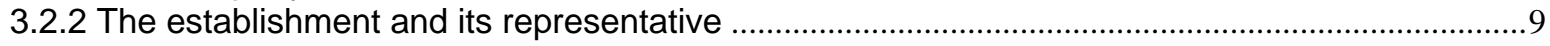

3.3 Influences that can be controlled by the researcher .................................................................11

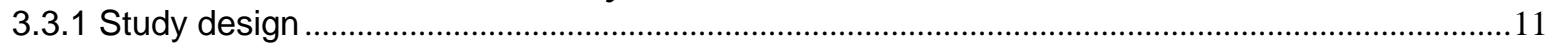

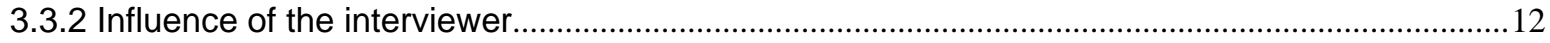

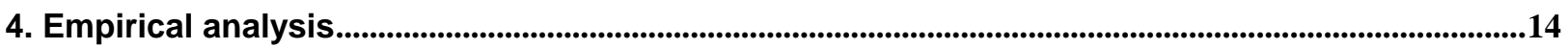

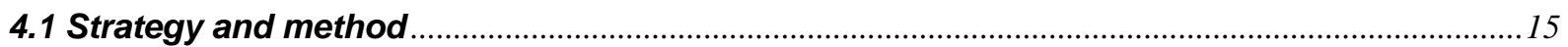

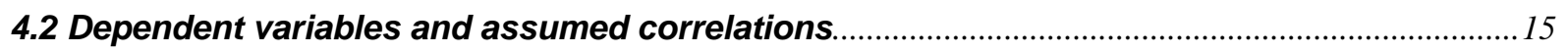

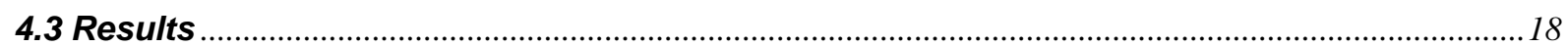

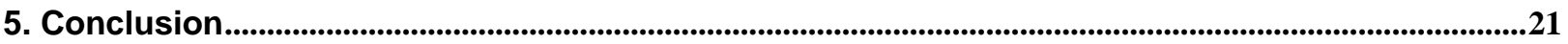

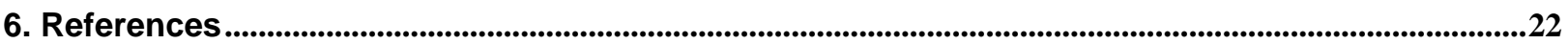

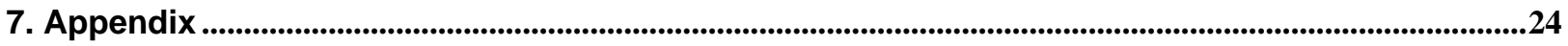

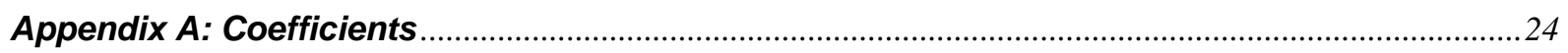

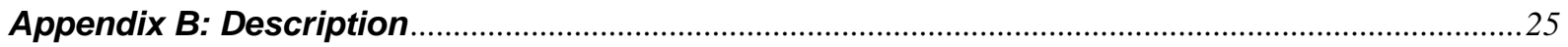

\section{Acknowledgements}

We would like to thank Lutz Bellmann, Guido Heineck, Hans Kiesl and Alexandra Schmucker for constructive criticism, ideas and amendments. The authors remain solely responsible for the content. 


\section{Introduction}

With the IAB Establishment Panel the Institute for Employment Research (Institut für Arbeitsmarkt- und Berufsforschung - $\mathrm{IAB}$ ) has conducted a large-scale annual establishment survey in western Germany since 1993 and also in eastern Germany since 1996, covering some 15,500 establishments in the meantime. In this panel survey the establishments are asked in face-to-face interviews ${ }^{1}$ to provide information on key determinants of employment. The IAB Establishment Panel is a survey in which the same establishments are contacted each year. New establishments are added to the sample each year in order to depict structural change. Furthermore additional establishments have to be included in the sample to replace those which have dropped out of the sample in the course of time. For despite all efforts, one problem arises in every survey: individual establishments' unwillingness to participate, which leads to so-called non-response.

Two forms of non-response can be distinguished. First, an establishment may refuse to participate in the survey at all (unit non-response). Second, participating establishments may fail to answer individual questions in the questionnaire (item non-response). Both types of nonresponse can lead to biased results if the cases of non-response are not random. Unit nonresponse leads to greater problems, however, as no interview is available for these establishments and it is not just the case that individual questions are not answered.

Experience made with the IAB Establishment Panel shows that the willingness of establishments surveyed for the first time to participate in the survey is clearly lower, at 36 percent, than that of establishments which have already been included in the survey at least once. Furthermore the unit non-response of establishments surveyed for the first time has increased in the past few years. The willingness of the panel establishments, in other words the repeat respondents from previous years, to complete the questionnaire is considerably higher at about 80 percent. There is no indication that the willingness to participate is declining over the years. The advantage of panel surveys is also that a wealth of establishment information is available from previous years for the establishments which have been surveyed repeatedly but which no longer respond and this can be used to model the non-response process. On the other hand little information is available about the establishments which are included in the survey for the first time.

It is important to analyse the non-response processes in order to gain the most precise insight possible into the survey process. The findings obtained in this way make it possible to optimise the fieldwork management, thus contributing to quality improvements and possibly to cost re-

\footnotetext{
${ }^{1}$ The interviews are conducted by TNS Infratest München on behalf of the Institute for Employment Research.
} 
ductions. In addition to this, the analyses can reveal any selectivities that may lead to biased estimates. The representativeness of the projection of all variables can also be jeopardised by possible selectivities. Furthermore, in panel surveys selectivities may intensify over time. The aim of this paper is to examine the unit non-response of establishments which have already taken part in the survey at least once and are approached again. On the basis of an extended conceptual framework for establishment surveys, determinants that influence the non-response process are to be brought out. For the first time for establishment surveys the interviewer's influence on the success of the interview is taken into account both in the conceptual framework and in the analyses. 


\section{Different types of unit non-response}

As already mentioned, only unit non-response is examined in the following. Although the IAB Establishment Panel is a panel survey, not only the establishments that were surveyed in the previous year are included each year, but also new establishments. This is done firstly in order to depict structural changes in the economy by incorporating new establishments and secondly in order to compensate for establishments which dropped out in previous years (see Fischer et al. 2009: 137). Both types of establishment (new respondents and repeat respondents) are thus found in every wave of the IAB Establishment Panel. Unit non-response may occur in both cases. In the following we concentrate on the cases of non-response that occur when an establishment has already taken part in the study at least once.

Two types of unit non-response are distinguished in the rest of the paper: ${ }^{2}$ cases of nonresponse that occur because it was not possible to contact the establishment ("noncontacts") and cases in which it was possible to contact the establishment but participation in the interview was refused.

There are various reasons why contacting an establishment may fail (Rendtel 2002):

- Some establishments can not be contacted because they no longer exist due to insolvency or plant closure. These cases of non-response are also known as neutral nonresponse as they depict structural change and are not survey errors.

- Another possible reason is that the address drawn for the sample is incorrect. This may be because the establishment has relocated and could no longer be traced. Secondly, incorrect information in the address file can not be ruled out. This can result in individual establishments not being found because it is not possible to establish the correct address.

- In individual cases it may also not be possible to contact an establishment for other reasons (e.g. poor accessibility). Good fieldwork management should prevent this, however, as establishments are generally accessible during usual business hours.

The second type of non-response is where the representatives of an establishment actually refuse to participate and it is not possible to persuade them to cooperate. ${ }^{3}$ There are diverse

\footnotetext{
${ }^{2}$ For household and individual surveys Groves et al. (2004: 170) distinguish a third type, which is inability to participate in surveys, for example because the respondent does not understand the language. We consider this type of non-response to be unimportant for establishment surveys, however, as language barriers do not constitute a problem in the business environment.

${ }^{3} \mathrm{~A}$ special form of this in the IAB Establishment Panel concerns establishments which are contacted in one year and refuse to participate in the current interview but which, when asked, explain that they will be available for an interview again in the following panel wave. This type of non-response ("non-
} 
reasons for non-response after contact has been made and these are the focus of our attention in the remainder of this paper. In order to better understand refusal to participate and to be able to model it, a conceptual framework for the decision to participate is first presented below. For this the interview is regarded as an interaction between the interviewer and the representative of the establishment, which ultimately determines the respondent's decision. 


\section{Explaining the decision to participate in establishment surveys}

\subsection{A conceptual framework}

Extensive studies have been conducted into the reasons why people refuse to take part in individual and household surveys (see on this subject Schnell/ Hill/ Esser 2005 and Groves et al. 2004: 176). However, little research has so far been conducted into the processes and reasons behind the willingness or refusal to participate in establishment surveys. ${ }^{4}$ For instance, although it is also individuals who are interviewed in company or establishment surveys, they are not asked about their personal circumstances or opinions but are interviewed as representatives of an organisation, so not only individual influences have to be taken into account but also the organisational context (see Tomaskovic-Devey/ Leiter/ Shealy 1995).

In order to better comprehend the decision of an establishment representative as to whether or not to participate, a conceptual framework for participation in a survey is first presented. Willimack/ Nichols/ Sudman (2002: 222) took the framework for household surveys which was developed by Groves/ Couper (1998: 30) and applied it to establishment surveys. However, this conceptual framework does not include the interviewer's influence on the respondent's willingness to participate. Figure 1 shows an extended conceptual framework for establishment surveys which also takes into account the interviewer's influence on the decision to participate. As with household surveys, two groups of factors can be determined which have an influence on the success of an interview: those which can be influenced by the researchers or by the study design (right-hand column of Figure 1), and those which can not be controlled (left-hand column of Figure 1).

If the non-controllable factors are examined first, then in household surveys these are the social environment (e.g. the economic situation or the neighbourhood), the household (household structures) and the characteristics of the head of the household (see Groves/ Couper 1998: 31 $\mathrm{ff})$. In the case of establishment surveys, these two groups of influencing factors can be equated with the company environment, the establishment (company structure/culture) and the characteristics of the establishment representative.

Analogous to household surveys, the factors that can be influenced by the researchers include on the one hand the survey design and on the other hand the selection and deployment of the interviewers. The meeting between respondent and interviewer when the interview is conducted or when contact is first established results in an interaction which decides whether the respondent will participate in the study or not. Although it is the respondent who makes the decision about whether or not to take part in the interview, the interviewer can have a

\footnotetext{
${ }^{4}$ See Hartmann/Kohaut (2000): 611 on this subject
} 
considerable influence on the decision. In the following the individual influencing factors are explained in more detail.

Figure 1: Conceptual framework for the decision to participate

Non-controllable

influencing factors

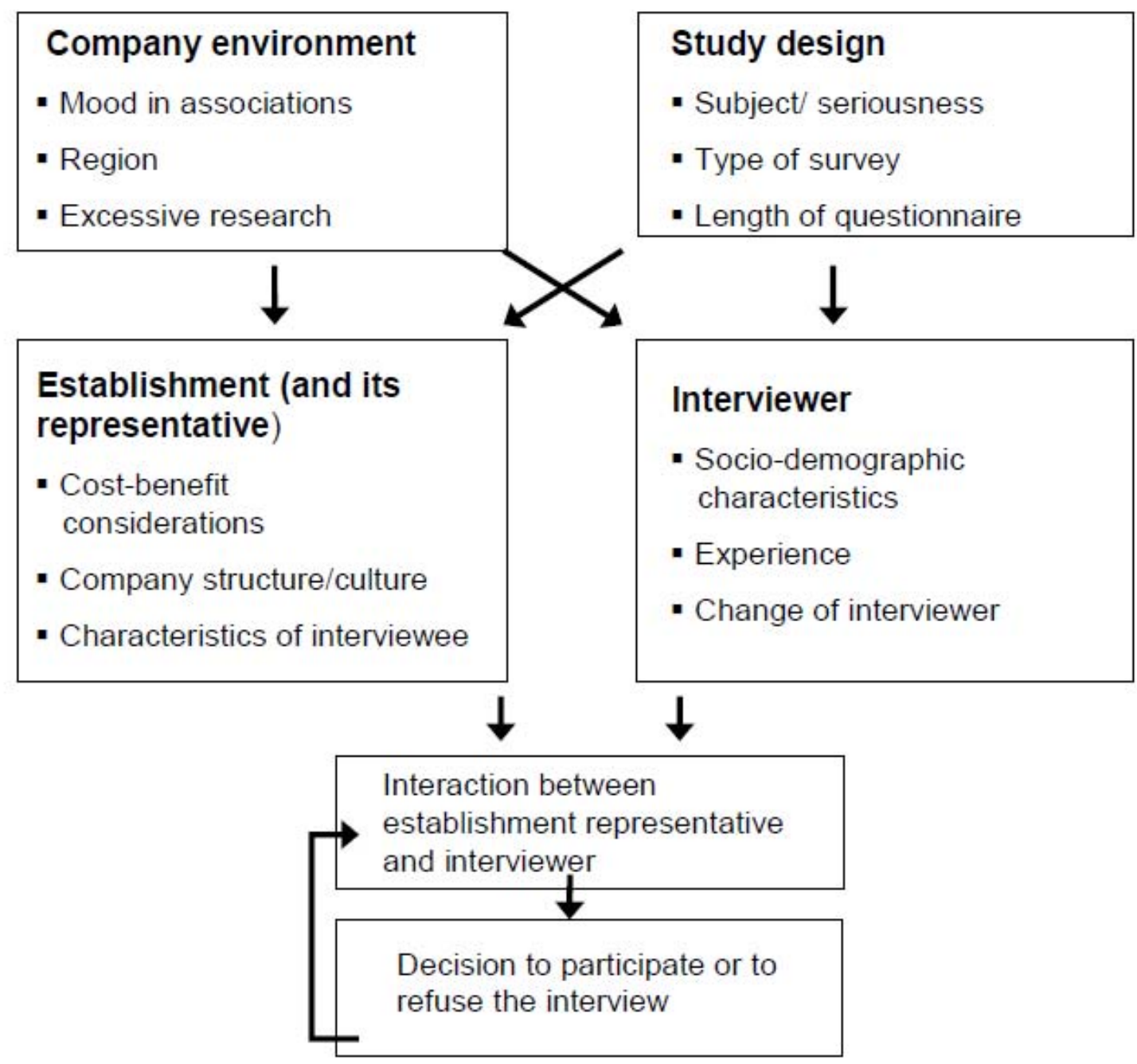

Controllable

influencing factors

\section{Study design}

Subject/ seriousness

Type of survey

Length of questionnaire

\author{
(a)
}


has so far been conducted into how the environment of an establishment influences its participation behaviour. It can be assumed, however, that the situation of the economy as a whole, the mood in employers' associations and also expectations regarding future developments have a certain impact on the fundamental willingness to take part in a survey.

An excessive amount of research concerning establishments is generally regarded as a reason for refusal to participate in a survey (see e.g. Groves et al. 2004: 176). It is hardly possible for the study design to influence the fact that firms may be confronted by a multitude of other surveys, some of which are also obligatory. At best the researchers can try to conduct their survey at a time when the fewest possible other surveys are being conducted in the firms. For this reason the surveys for the IAB Establishment Panel are carried out mid-year in order to avoid overlaps with other surveys which are mainly conducted at the end of the year.

\subsubsection{The establishment and its representative}

In the conceptual framework for the decision to participate in business surveys the household and the head of the household are replaced by the establishment and the establishment representative. An theory of action model of respondent behaviour forms the basis for the decision to participate. The central theoretical assumption is that people wish to maximise their utility by their action. A contact person in an establishment is more likely to participate in a survey the higher the expected utility and the lower the costs resulting from the survey are. ${ }^{5}$ On the basis of these considerations it is possible to derive determinants of participation behaviour for business surveys too. In this context Tomaskovic-Devey/ Leiter/ Shealy (1995: $80 \mathrm{ff}$ ) and Schnabel (1997: $161 \mathrm{ff}$ ) identify three aspects: authority to respond, capacity to respond and motive to respond.

"Authority to respond" refers to the degree to which the respondent has the formal or informal authority to provide an answer (Schnabel 1997: 126). This depends on the size of the establishment and the degree of independence from external decision-makers. As establishment size increases, so too does the vertical complexity and thus also the probability that the authority of the contact person in the establishment is no longer sufficient for answering the survey questions. Obtaining permission to participate in a survey costs time and money and is therefore more likely to lead to a refusal to participate. The same applies for dependent business units, for example branch offices, which may have to obtain authorisation from parts of the company further up the hierarchy.

The second aspect, "capacity to respond", refers to the respondent's ability to provide reliable answers to the questions asked. Here, too, the size of the establishment is an important char- 
acteristic. As the size increases the probability of one person not having all of the information grows. Obtaining the information raises the transaction costs and thus tends to increase the likelihood of participation being refused. This effect could be reversed, however, in large establishments with professional personnel information systems and publication obligations, since here relevant data can be accessed centrally. ${ }^{6}$

Both points indicate that it makes sense when conducting business surveys to interview people in high positions whenever possible, as they then have both the authority and the capacity to give reliable answers. For this reason, in the IAB Establishment Panel it is always the managers, the heads of offices or the owners of the establishments that are approached.

The third group of factors cited by Tomoskovic-Devey/ Leiter/ Shealy (1995), the "motive to respond", comprises the preferences and the interest of the company regarding the exchange of information. Here it is corporate policy that decides (or helps to decide) whether participation in a survey is supported or not. What plays a role in this respect is whether an establishment is in principle interested in the research findings obtained, for example in order to reduce its own planning uncertainty. It is assumed that listed companies and establishments which are heavily dependent on external resources are more interested in being informed about their environment and providing information themselves (see Schnabel 1997: 163). In this context it is important that the establishment interprets the survey as relevant for the establishment itself and the results as interesting. Corporate policy is difficult to operationalise for analyses of nonresponse, however. The legal form, the size of the establishment once again and the response behaviour of the establishment representative can, however, provide some indications. Besides corporate policy, personal motives on the part of the person representing the establishment also have a considerable influence on the willingness to participate. Respondents who identify strongly with the firm will also follow corporate policy when deciding whether to participate. In addition personal considerations may be of importance, depending on whether the survey is perceived as a burden or as a diversion, or whether participation can be used to prove one's own competence or to express (political) statements. The IAB Establishment Panel, however, does not contain information about the establishment representative who was interviewed, so these influences can not be modelled.

\footnotetext{
${ }^{5}$ For the derivation of the theoretical considerations see Hartmann/Kohaut (2000: $612 \mathrm{f}$ ) and the paper by Schnabel (1997: $158 \mathrm{ff})$, in which a full action-theory model is developed.
} 


\subsection{Influences that can be controlled by the researcher}

\subsubsection{Study design}

The right-hand side of Figure 1 shows the two groups of influencing factors that can be set and therefore controlled by the researcher. Study design is of considerable importance in this respect, as it has a decisive influence on unit non-response. Various measures are intended to make the participation decision easier for the establishment representative or to influence the decision positively. In the IAB Establishment Panel these measures were designed in such a way that they anticipate respondents' expected reactions and influence them positively if possible.

The perceived legitimacy and seriousness of the survey is likely to have an important influence on the willingness to respond to business surveys, too. It can be assumed that establishment representatives are more likely to respond if they have the feeling that the survey is being conducted on behalf of serious organisations. For this reason the establishments in the IAB Establishment Panel receive two letters announcing the survey before the interviewer makes contact. One of the letters is signed by the president of the Federal Confederation of German Employers' Associations (Bundesvereinigung der deutschen Arbeitgeberverbände) and the other one by the CEO of the Executive Board of the Federal Employment Agency (Bundesagentur für Arbeit). Both of the letters briefly explain the aim of the survey and ask for support. The two letters also announce that contact will be made by telephone. After that the interviewers are required to telephone the establishment to arrange an appointment with as senior a person as possible in the establishment.

From theoretical considerations the length of the interview should be negatively correlated with the decision to participate, as the burden and thus also the opportunity costs increase along with the length of the interview. This correlation was not so clear for various individual and household surveys, however (see Lipps 2007: 47). We know of no relevant empirical studies for business surveys.

As the IAB Establishment Panel is a survey which is repeated annually with the same establishments, the questionnaire also remains largely the same each year. The length of the questionnaire is fixed at 24 pages. However, an attempt is made to gain the interest of the establishments by including current, politically relevant questions.

Establishments which have already taken part in the survey at least once and refuse to participate in the current wave are asked whether they may be approached again in the following

\footnotetext{
${ }^{6}$ In addition the questionnaire of the IAB Establishment Panel is designed in such a way that it can be left in the establishment if individual questions could not be clarified during the face-to-face interview.
} 
wave. In this way some of the refusers can be contacted again and persuaded to participate in the next wave of the survey.

\subsubsection{Influence of the interviewer}

The interviewer with his/her experience and behaviour can also have a considerable influence on the respondent's willingness to cooperate, even if it is ultimately the respondent who makes the decision as to whether to respond to the survey. The person being interviewed responds (also unconsciously) to observable and non-observable characteristics of the interviewer. Therefore the socio-economic characteristics of the interviewer are of great importance because they serve as clues for the respondent from which s/he draws conclusions about the intention and seriousness of the survey. This can be found in individual and household surveys (see for example Groves/ Couper 1998: 36). For instance the respondent uses the interviewer's age or sex to form an opinion about the intention of the interview. An interviewer who is classified as trustworthy due to his personal appearance / manner can persuade a person to participate in a survey more easily than an interviewer who does not show these characteristics. It can plausibly be assumed that this connection is also of importance for business surveys, where the interviewer's respectable, professional appearance is seen as an "entrance ticket" to the establishment. The age and education level of the interviewers for the IAB Establishment Panel are recorded.

Many studies on individual surveys (see Pickery/ Loosveldt/ Carton 2001: 510) and on household surveys (see Groves/ Couper 1996: 69, Groves/ Couper 1998: 36) stress the importance of an interviewer's experience. Experienced interviewers can draw on a wide range conversation techniques that they can use to persuade the respondents to participate in a survey. In a multitude of interviews they have learned which allusions, phrases or descriptions they can use to describe convincingly what the survey is about depending on the behaviour of the person they have contacted. Owing to their experience, these interviewers are able to anticipate the respondents' reactions and to respond accordingly.

Going beyond the concept developed by Groves/ Couper (1998), panel surveys such as the IAB Establishment Panel involve the additional aspect of annual repetition. If an interviewer has already successfully conducted an interview in an establishment, experience made with the IAB Establishment Panel (see Hartmann/ Kohaut 2000: 613) shows that changing the interviewer between two surveys reduces the probability of participation. Obviously a kind of mutual trust is built up between interviewer and interviewee that simplifies a repeat survey. In addition, one can put forward the argument of the inertia of existing company structures (path dependence), which leads to (participation) decisions, once made, being maintained (on the subject of path 
dependence see Schreyögg/ Koch/ Sydow 2004: 1301). In this respect care is also taken in the fieldwork to ensure that the establishments are contacted by the same interviewer each year.

When an interviewer and a respondent come together, an interaction takes place which decides whether the interview can be conducted or not. Here all of the factors described earlier in the paper influence the interview situation to a greater or lesser extent. Whether or not a full interview is achieved then depends on the interviewer's skill in guiding the situation and keeping up the conversation. 


\section{Empirical analysis}

In the IAB Establishment Panel two types of non-response are distinguished (see Section 2): first, cases of non-response that occur because it was not possible to contact the establishment (in particular due to the establishment closing down or becoming defunct) and second, nonresponse due to refusal to participate. This type also includes establishments that refuse to take part in the current survey but may be contacted again the following year.

Figure 2: (Non-)Participation in the IAB Establishment Panel 2006

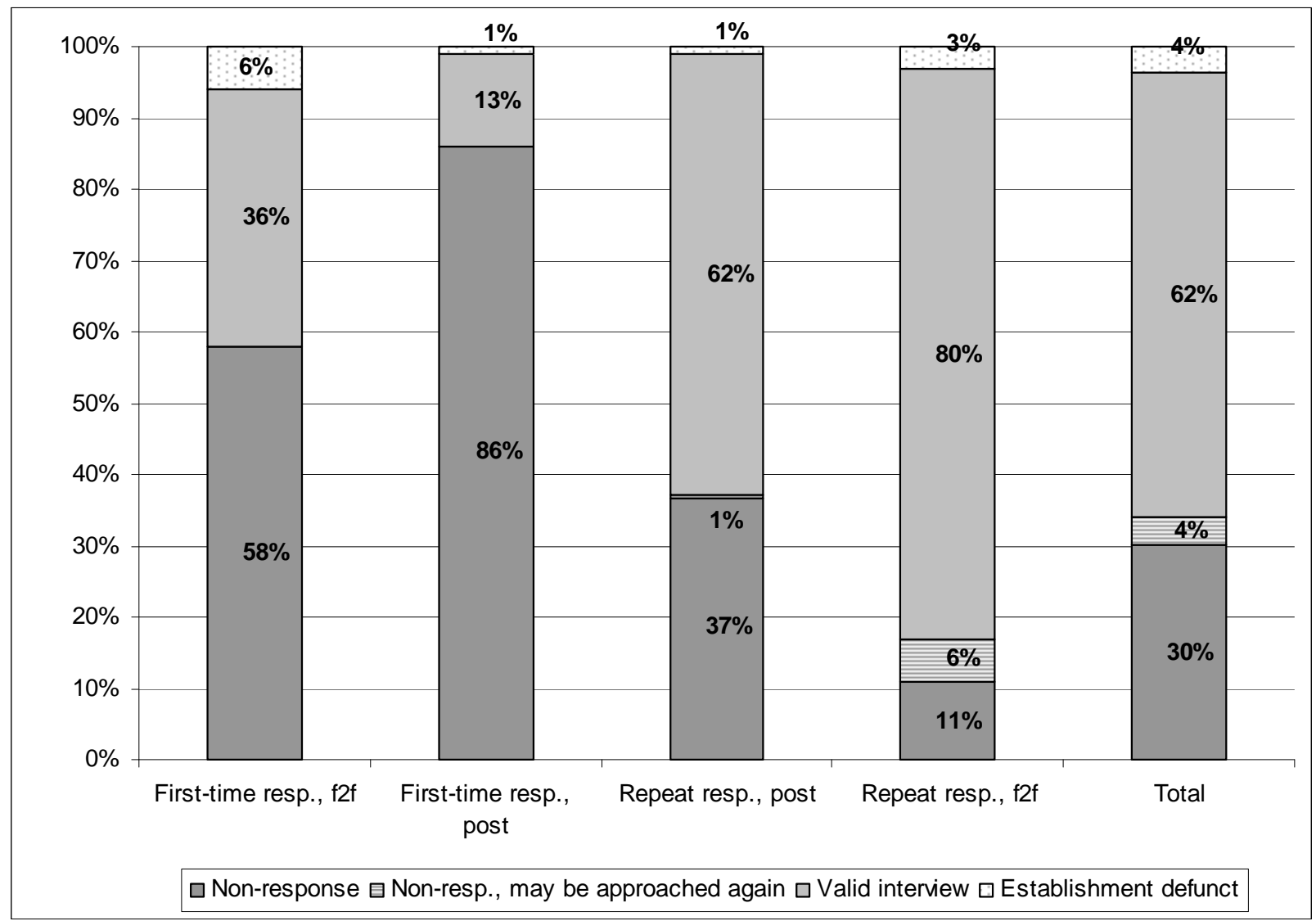

Source: IAB Establishment panel 2006, organisation file, own calculations

Figure 2 shows the different types of non-response for establishments included in the survey for the first time and those repeating participation. The graph also distinguishes between postal and face-to-face (f2f) surveys. In the 2006 wave a total of $30 \%$ of the establishments did not participate, another $4 \%$ did not participate in this wave but would be available again for the following wave. A further $4 \%$ of the establishments were defunct and could therefore no longer participate in the survey. However, the vast majority of the establishments contacted (62\%) participated (again). Moreover, it can also be seen from the graph that establishments which have participated in the IAB Establishment Panel at least once refuse to participate again less frequently than establishments included in the survey for the first time. It also becomes clear 
that face-to-face interviews with an interviewer are obviously more successful than written surveys. Accordingly non-response is lowest among the establishments in repeat face-to-face interviews and highest among the establishments approached for the first time and by post. These proportions have remained essentially stable over time, though in the last waves there was a slight decline in the willingness of establishments approached for the first time to participate (Fischer et al. 2009: 140 f).

\subsection{Strategy and method}

The following analyses refer to establishments included in the 2006 wave which had previously participated in the survey, in other words repeat respondents, and which were to be surveyed by means of face-to-face interviews. This restriction is made mainly because this is the only group for which data about the interviewers and relevant information about the establishment are available. This makes it possible to analyse the different aspects of the theoretical framework.

The reasons for establishments that took part in the 2005 (or 2004) survey refusing to participate in 2006 are examined. Cases are regarded as non-response when the establishment still exists, in other words is not defunct, but was not willing to participate in the current survey (irrespective of whether the establishment is prepared to participate in the following year or not). A dummy variable is formed as a dependent variable, which takes on the value one if the establishment does not participate and the value zero if it does. For the multivariate analysis clustered logit models are estimated, due to the two levels of analysis (interviewers who can each interview more than one establishment).

The independent variables are generated from the details given by the establishment at the time of the last valid interview - as a rule the previous year. In the case of establishments that did not participate in the previous year but were contacted again in 2006, the information is accordingly from 2004. In addition background information about the "survey history" of the establishment and information about the interviewer is merged. This information comes from TNS Infratest Sozialforschung and was merged with the dataset after anonymisation ${ }^{7}$.

\subsection{Dependent variables and assumed correlations}

In the following sections the dependent variables used in the different estimates and the assumed correlations with participation or non-participation are described ${ }^{8}$.

\footnotetext{
${ }^{7}$ The IAB Establishment Panel does not contain details about the establishment representative who was interviewed, so the influences arising from the interaction between the interviewer and the respondent can not be modelled.

${ }^{8}$ The aspects of company environment and the study design are not included in the analyses, however, as no suitable variables are available for this.
} 


\section{The establishment and its representative}

On the basis of the theoretical considerations it can be assumed that the economic situation plays a role in the decision to participate even if the direction is not clear at first. On the one hand it is conceivable that establishments are happy to speak about successes, on the other hand especially establishments that are currently experiencing a crisis may report about their difficult situation in the hope of receiving assistance. Two dummies are therefore included as proxy variables for the economic situation of the establishment. They report whether employment increased or decreased (or remained at the same level) between the last two surveys.

It can be assumed that as the size of the establishment increases it becomes more difficult, more time-consuming and more costly to find a person who is permitted to answer the questions asked (authority to respond) and who has the resources to obtain the required information (capacity to respond). Small establishments can therefore be expected to refuse to participate less often. Establishment size is taken into consideration by including a total of nine dummies in the estimates. In this way the disproportionate stratification of the sample of the IAB Establishment Panel is taken into account at the same time. Owing to the disproportionality of the sample, sector affiliation is also taken into account in the estimate by means of 16 dummies.

Another dummy indicates whether an establishment is an independent company or a company headquarters. In such establishments it should be easier to procure the information than is the case in a dependent establishment, where it may be necessary first to clarify with a superior department what information, if any, may be passed on. For this reason there is presumed to be a negative correlation with unit non-response.

Owing to their stronger dependence on external resources, corporations (Kapitalgesellschaften) are expected to be more interested in the research findings (motive to respond) and thus also more willing to participate. Therefore dummy variables indicate whether the establishment is organised as a corporation, a partnership (Personengesellschaft) or in another legal form.

In addition a number of other variables are included which, although they do not directly depict the establishment's or its representative's interest in participating, can nonetheless be taken as indicators:

It can be assumed that in surveys establishments do not like to pass on information which is perceived as sensitive and is difficult to procure. Missing replies to such questions (item nonresponse) in the previous year can therefore be interpreted as a first indication of refusal to participate in the following wave. For this reason two dummies are included in the estimates which show whether the establishment did not answer the questions about total wages and 
salaries and total investments ${ }^{9}$ in the last survey. For similar reasons another dummy is included which shows whether the establishment did not participate in the survey in the previous year. Here, too, a positive correlation with the likelihood of non-response is expected.

The influence of the duration of participation, in other words the number of times that an establishment has taken part in the survey in the past, is uncertain in theoretical terms. On the one hand it can be presumed that the costs of participation decrease each time as many questions remain the same and the respondent already knows how to answer them. On the other hand a certain weariness on the part of the respondent can not be ruled out. The duration of participation is therefore taken into account in the estimate.

\section{Study design}

With establishments that have participated in the survey more than once it may happen that, as a result of reorganisation in the establishment, outsourcing or insourcing parts of the establishment or for other reasons, the unit interviewed in the previous year no longer corresponds with the unit interviewed in the current survey. In the IAB Establishment Panel the employment figures from the previous year's questionnaire are used to ascertain whether the units correspond with one another. If differences arise, it is determined whether the establishment located is still connected with the establishment which was originally included in the survey. If such connections can be established, an interview is conducted and these facts are documented (for details see Fischer et al. 2009: 139f). It is presumed that willingness to participate declines in such cases where the unit involved in the survey changes, as there may often be serious reorganisations behind this which may also result in a change of contact person. Therefore a dummy is included in the analysis which shows whether the unit surveyed in the previous year was different from that in the years before. It can be assumed that such a change also increases the likelihood of non-response in the following year.

In addition a dummy is included which reports whether the questionnaire was mainly or entirely completed by the establishments themselves. In such cases a higher probability of nonresponse is expected for two reasons: first, self-completion is a sign that processing the questionnaire requires a lot of time and effort for the establishment and second, the presumed positive effects of the interviewer are lost either partially or entirely.

Up until the 2001 wave of the IAB Establishment Panel all establishment identification numbers that had ever been included in the gross sample in one of the waves and did not take part or no longer took part in the survey were excluded for all further waves. This means that they were

\footnotetext{
${ }^{9}$ The variables with the most missing values in the IAB Establishment Panel are turnover and intermediate consumption as a proportion of this. As these variables are not included in the survey for banks, insurance companies and the public service, however, they are not taken into account here.
} 
no longer available for sampling. Since the 2002 wave establishment numbers that had once belonged to the gross sample but had in the meantime dropped out of it have been able to be drawn again after a waiting period. The reason for this decision was that the population in some sectors or some federal states in the upper establishment size classes was almost exhausted and therefore problems had arisen in filling cells in the stratification matrix. It is thus possible for an establishment which had already participated in the survey in the past to be approached again. In all of the estimates a corresponding dummy is included and it can be assumed that an establishment which decided not to take part in the survey at some time in the past is more likely to do so again.

\section{Interviewers}

The length of time that the interviewer has belonged to the interview team of TNS Infratest Sozialforschung is included in the estimates. As it can be assumed that experienced interviewers also have better strategies, a negative correlation with the likelihood of non-response is expected here.

In addition each interviewer's workload is taken into account by means of the (log of the) number of interviews conducted in one wave. On the one hand it is conceivable that interviewers with a heavy workload might not work so carefully and that the willingness of establishments to participate suffers as a result. On the other hand it is not implausible to assume that particularly successful interviewers also conduct a particularly large number of interviews.

Finally it is taken into consideration whether there has been a change of interviewer. As in such cases the contact and the mutual trust between the interviewer and the establishment or its representative has to be built up from scratch again, a higher probability of non-response is expected here.

In addition a number of socio-demographic characteristics are controlled for by including the interviewers' age, sex and education level.

As a further control variable it is taken into account whether the business premises are located in eastern or western Germany.

\subsection{Results}

Table 1 shows the results of the estimate. In each case the marginal effects are displayed ${ }^{10}$. On the whole many of the assumed correlations are confirmed by the analysis.

\footnotetext{
${ }^{10}$ A table showing all the included variables and the coefficients, as well as descriptive statistics about the individual variables can also be found in the appendix.
} 
Table 1: Marginal effects ${ }^{+}$

\begin{tabular}{|c|c|c|}
\hline Name & Marginal effect & z-value \\
\hline Independent company / company headquarters (dummy) & $-0.016^{*}$ & -2.25 \\
\hline \multicolumn{3}{|l|}{ Legal form (reference: partnership (Personengesellschaft)) } \\
\hline Corporation (Kapitalgesellschaft) & 0.014 & 1.61 \\
\hline Other legal form & -0.012 & -1.18 \\
\hline Missing value for total wages and salaries (dummy) & $0.037^{\star *}$ & 3.55 \\
\hline Missing value for total investments (dummy) & 0.024 & 1.65 \\
\hline Did not participate in the previous year (dummy) & $0.449^{\star \star}$ & 15.04 \\
\hline Already refused to take part in panel in the past (dummy) & 0.028 & 1.65 \\
\hline Duration of participation in years & $-0.007^{* \star}$ & -6.68 \\
\hline Different unit surveyed in the previous year (dummy) & $0.098^{\star \star}$ & 2.75 \\
\hline \multicolumn{3}{|l|}{ Development of employment (reference: no change) } \\
\hline Increase in employment & 0.006 & 0.81 \\
\hline Reduction of employment & 0.007 & 0.95 \\
\hline $\begin{array}{l}\text { Questionnaire completed partly or entirely by the establish- } \\
\text { ment itself (dummy) }\end{array}$ & $0.054^{\star \star}$ & 5.07 \\
\hline $\begin{array}{l}\text { Interviewer's education level ( } 1=\text { lower secondary school leav- } \\
\text { ing certificate, } 5=\text { university degree) }\end{array}$ & 0.003 & 0.89 \\
\hline No. of years that interviewer has belonged to interviewer team & -0.001 & -1.31 \\
\hline Interviewer's age & -0.000 & -0.68 \\
\hline Interviewer's sex male (dummy) & -0.000 & -0.03 \\
\hline Change of interviewer (dummy) & $0.117^{* *}$ & 3.30 \\
\hline No. of interviews in the wave (log) & $-0.029 * \star$ & -4.91 \\
\hline Establishment in eastern Germany (dummy) & $-0.028^{\star}$ & -2.56 \\
\hline \multicolumn{3}{|l|}{ Establishment size (reference: 1-4 employees) } \\
\hline $5-9$ employees & -0.006 & -0.61 \\
\hline 10-19 employees & -0.019 & -1.67 \\
\hline 20-49 employees & 0.002 & 0.15 \\
\hline 50-99 employees & 0.023 & 1.71 \\
\hline 100-199 employees & $0.031^{*}$ & 2.02 \\
\hline 200-499 employees & $0.038^{*}$ & 2.29 \\
\hline 500-999 employees & $0.054^{\star \star}$ & 2.61 \\
\hline 1000-4999 employees & $0.075^{\star \star}$ & 2.81 \\
\hline $5000+$ employees & 0.046 & 0.91 \\
\hline $\mathrm{N}$ & 14902 & \\
\hline Pseudo $\mathrm{R}^{2}$ & 0.110 & \\
\hline \multicolumn{3}{|l|}{ Robust standard errors, clustered by interviewers } \\
\hline${ }^{*} p<0.05,{ }^{* \star} p<0.01$ & & \\
\hline
\end{tabular}

As was presumed, large establishments refuse to participate again more frequently than small establishments $^{11}$. Furthermore it can be seen, also in line with the theoretical considerations, that independent companies and company headquarters are more likely to participate in the survey. The effect is relatively weak, however. Obviously the respondents in small establish-

\footnotetext{
${ }^{11}$ Although the effect of the establishment size dummy for the establishments with 5000 or more employees no longer differs significantly from zero, alternative specifications show clearly the linear correlation with establishment size.
} 
ments and independent companies are more likely to have the capacity as well as the authority to answer the questions in the IAB Establishment Panel. The costs involved in procuring the information are presumably lower for the respondents in such establishments. The negative, though relatively small, effect of the duration of participation also indicates the significance of the cost argument. Establishments that have already participated in the survey for some time less frequently refuse to participate again. In these cases it is apparently easier for the respondent to obtain the desired information.

The motivation to participate in the survey is also of decisive importance. For instance, establishments which gave no details about the rather sensitive total wages and salaries in the last survey tend to refuse participation more frequently. A refusal to participate in the previous year increases the probability of a further refusal most clearly. It is also in line with expectations that a change in the unit surveyed (in the last wave) reduces the willingness to participate considerably, albeit less strongly than refusal in the previous year.

In addition it can be ascertained that establishments completing the questionnaire partly or entirely themselves results more frequently in a refusal to participate. This may be due to the higher costs involved in the respondent obtaining the information or to the missing positive influence of the interviewer ${ }^{12}$.

Neither the economic situation of the establishment nor its sector affiliation has any influence on participation in the survey, however. In addition, it can be seen that establishments in eastern Germany refuse to participate slightly less often than those in western Germany.

When examining the interviewer effects, the first thing that stands out is that the interviewer's individual characteristics, education level, experience, age and sex, have no influence on participation. Only two variables yield significant results. First, it is visible that a change of interviewer increases the probability of non-response to a similar extent to a change in the unit surveyed. Second, interviewers who conduct a particularly large number of interviews also appear to be more successful. Here establishments refuse to participate again less frequently.

\footnotetext{
${ }^{12}$ This effect can also be found in an alternative specification of the estimate in which all establishments were included, i.e. also those surveyed by post. This type of survey, in which the use of interviewers is not possible, leads systematically to clearly higher rates of non-response.
} 


\section{Conclusion}

The analyses of refusal to participate in the IAB Establishment Panel show that the observed cases of non-response can mainly be reconciled with the conceptual framework presented. Most of the variables examined remain without significant influence in the estimated model or can be influenced by the study design or by controlling the use of the interviewer. To sum up, it can be recorded that the results confirm the theory of action decision model for the respondent's behaviour. If the respondent has the authority to provide relevant information, is able to give reliable answers to the questions with a justifiable amount of effort and is interested in the survey in business terms, participation is less frequently refused. The main influential factors are accordingly the size of the establishment, the independence of the establishment surveyed, refusal to provide sensitive information in the previous year and a number of variables which indirectly suggest motivation (duration of participation, refusal in the previous year).

The results also confirm the central significance of the interaction between the respondent and the interviewer. If one of the two individuals changes, the probability of further participation falls clearly. Completing the questionnaire (partly) in writing without an interviewer being present also results in less frequent participation.

The size of the establishment and its location (western or eastern Germany) need to be examined in more detail, however, as non-response is more likely in large and/or western German establishments. ${ }^{13}$ This relationship must be borne in mind when evaluating the IAB Establishment Panel. The non-response structure can become problematic if the variables cited are also causally related to the outcome variables. The consequences that these selectivities could have for evaluations using the data of the IAB Establishment Panel need to be clarified in further research ${ }^{14}$.

\footnotetext{
${ }^{13}$ In the projection of the IAB Establishment Panel, cases of non-response are balanced (?) by sector, establishment size and federal state. For more details see Fischer/ Janik/ Schmucker (2009: $140 \mathrm{ff})$.

${ }^{14}$ A first analysis of this can be found in Bellmann et. al. (2005).
} 


\section{References}

Bellmann, Lutz, Calienda, Marco, Hujer, Reinhard, Rodrigues, Paulo (2005): ItemAntwortausfälle im IAB-Betriebspanel: Modellansätze und ökonometrische Schätzung am Beispiel der Bruttolohn- und Gehaltssumme. Beitrag zur 1. Nutzerkonferenz zu den Daten der BA und des IAB, 15. und 16. Juli 2005.

Fischer, Gabriele; Janik, Florian; Müller, Dana; Schmucker, Alexandra (2009): The IAB Establishment Panel - things users should know. In: Schmollers Jahrbuch. Zeitschrift für Wirtschaftsund Sozialwissenschaften, Jg. 129, H. 1, S. 133-148.

Groves, Robert M.; Couper, Mick P. (1996): Contact-Level Influences on Cooperation in Faceto-Face Surveys. In: Journal of Official Statistics, Vol. 12, No. 1, pp. 63-83.

Groves, Robert M.; Couper, Mick P. (1998): Nonresponse in Household Interview Surveys. USA: John Wiley \& Sons, Inc.

Groves, Robert M.; Fowler, Jr., Floyd J.; Couper, Mick P.; Lepkowski, James M.; Singer, Eleanor; Tourangeau, Roger (2004): Survey Methodology. Hoboken, New Jersey: John Wiley \& Sons, Inc.

Hartmann, Josef; Kohaut, Susanne (2000): Analysen zu Ausfällen (Unit-Nonresponse) im IABBetriebspanel. In: Mitteilungen aus der Arbeitsmarkt- und Berufsforschung, Jg. 33, H. 4, S. 609618.

Lipps, Oliver (2007): Attrition in the Swiss Household Panel. In: Methoden - Daten - Analysen. 1. Jg., Heft 1, S. 45-68.

Pickery, Jan; Loosveldt, Geert; Carton, Ann (2001): The Effects of Interviewer and Respondent Characteristics Response Behavior in Panel Surveys: A Multilevel Approach. In: Sociological Methods \& Research. Vol. 29, pp. 509-523.

Rendtel, Ulrich (2002): Attrition in Household Panels: A Survey. CHINTEX Working Paper \#4 Schnabel, Anette (1997): Teilnahmeverhalten bei Unternehmensbefragungen. In: Arbeit, 6. Jg.. Heft 2, S. 154-172.

Schnell, Rainer; Hill, Paul B.; Esser, Elke (2005): Methoden der empirischen Sozialforschung. München: Oldenbourg.

Schreyögg, Georg; Koch, Jochen; Sydow, Jörg (2004): Routinen und Pfadabhängigkeit. In: Schreyögg, Georg; von Werder, Axel (Hg.): Handwörterbuch Unternehmensführung und Organisation. Stuttgart: Schäffer-Poeschel, S. 1295-1304. 
Tomaskovic-Devey, Donald; Leiter, Jeffrey; Thompson, Shealy (1995): Item Nonresponse in Organizational Surveys. In: Sociological Methodology, Vol. 25, pp. 77-110.

Willimack, Diane K.; Nichols, Elizabeth; Sudman, Seymour (2002): Understanding Unit and Item Nonresponse in Business Surveys. In: Groves, Robert M.; Dillman, Don A.; Eltinge, John L.; Little, Roderick J.A: (Eds.): Survey Nonresponse. New York: John Wiley \& Sons, pp. 213 227. 


\section{Appendix}

\section{Appendix A: Coefficients}

\begin{tabular}{|c|c|c|}
\hline Name & Coefficient & z-value \\
\hline Independent company / company headquarters (dummy) & $-0.142^{\star}$ & -2.33 \\
\hline \multicolumn{3}{|l|}{ Legal form (reference: partnership (Personengesellschaft)) } \\
\hline Corporation (Kapitalgesellschaft) & 0.127 & 1.60 \\
\hline Other legal form & -0.116 & -1.15 \\
\hline Missing value for total wages and salaries (dummy) & $0.310^{\star \star}$ & 3.80 \\
\hline Missing value for total investments (dummy) & 0.204 & 1.78 \\
\hline Did not participate in the previous year (dummy) & $2.289^{* *}$ & 19.20 \\
\hline Already refused to take part in panel in the past (dummy) & 0.239 & 1.78 \\
\hline Duration of participation in years & $-0.061^{\star *}$ & -6.64 \\
\hline Different unit surveyed in the previous year (dummy) & $0.697^{\star \star}$ & 3.39 \\
\hline \multicolumn{3}{|l|}{ Development of employment (reference: no change) } \\
\hline Increase in employment & 0.056 & 0.82 \\
\hline Reduction of employment & 0.065 & 0.95 \\
\hline $\begin{array}{l}\text { Questionnaire completed partly or entirely by the establishment itself } \\
\text { (dummy) }\end{array}$ & $0.442^{\star *}$ & 5.54 \\
\hline $\begin{array}{l}\text { Interviewer's education level ( } 1=\text { lower secondary school leaving certifi- } \\
\text { cate, } 5=\text { =university degree) }\end{array}$ & $0.030^{*}$ & 0.89 \\
\hline No. of years that interviewer has belonged to interviewer team & -0.010 & -1.33 \\
\hline Interviewer's age & -0.003 & -0.68 \\
\hline Interviewer's sex male (dummy) & -0.003 & -0.03 \\
\hline Change of interviewer (dummy) & $0.826^{\star *}$ & 4.16 \\
\hline No. of interviews in the wave (log) & $-0.265^{\star \star}$ & -4.65 \\
\hline Establishment in eastern Germany (dummy) & $-0.256^{\star}$ & -2.54 \\
\hline \multicolumn{3}{|l|}{ Establishment size (reference: 1-4 employees) } \\
\hline $5-9$ employees & -0.058 & 0.09600 \\
\hline 10-19 employees & -0.179 & 0.11300 \\
\hline 20-49 employees & 0.018 & 0.11600 \\
\hline 50-99 employees & 0.199 & 0.11000 \\
\hline 100-199 employees & $0.261^{*}$ & 0.12000 \\
\hline 200-499 employees & $0.314^{*}$ & 0.12600 \\
\hline 500-999 employees & $0.427^{\star \star}$ & 0.14500 \\
\hline 1000-4999 employees & $0.566^{* \star}$ & 0.17000 \\
\hline $5000+$ employees & 0.365 & 0.35400 \\
\hline \multicolumn{3}{|l|}{ Sectors (reference: agriculture/hunting/forestry) } \\
\hline Mining/energy & -0.180 & -0.68 \\
\hline Food products/tobacco products & -0.148 & -0.60 \\
\hline Consumer goods & -0.150 & -0.63 \\
\hline Producer goods & -0.165 & -0.85 \\
\hline Capital goods / consumer durables & 0.051 & 0.27 \\
\hline Construction & 0,302 & 1,56 \\
\hline Wholesale and retail trade / repairs & 0.150 & 0,84 \\
\hline Transport / communication & 0.086 & 0.41 \\
\hline Financial intermediation & -0.003 & -0.01 \\
\hline Hotels and restaurants & $0.533^{\star \star}$ & 2.65 \\
\hline Education & 0.014 & 0.07 \\
\hline Health and social work & 0.139 & 0.74 \\
\hline Business services & 0.176 & 0.97 \\
\hline
\end{tabular}




\begin{tabular}{|l|r|r|}
\hline Name & Coefficient & z-value \\
\hline Other service activities & 0.188 & 0.89 \\
\hline Non-profit organisation & 0.125 & 0.50 \\
\hline Public administration & -0.215 & -0.99 \\
\hline Constant & -0.617 & -1.48 \\
\hline $\mathrm{N}$ & 14902 & \\
\hline F-test establishment size & $40.65^{\star \star}$ & \\
\hline F-test sectors & $41.84^{\star \star}$ & \\
\hline Pseudo ${ }^{2}$ & 0.110 & \\
\hline Robust standard errors, clustered by interviewers & & \\
\hline${ }^{\star} p<0.05,{ }^{\star \star} p<0.01$ & & \\
\hline
\end{tabular}

\section{Appendix B: Description}

\begin{tabular}{|c|c|c|c|c|}
\hline Name & $\begin{array}{l}\text { Mean } \\
\text { value }\end{array}$ & $\begin{array}{l}\text { Standard } \\
\text { deviation }\end{array}$ & Minimum & Maximum \\
\hline $\begin{array}{l}\text { Independent company / company headquarters } \\
\text { (dummy) }\end{array}$ & 0.765 & 0.424 & (1) & (1) \\
\hline $\begin{array}{l}\text { Legal form (reference: partnership (Per- } \\
\text { sonengesellschaft)) }\end{array}$ & 0.300 & 0.458 & 0 & 1 \\
\hline Corporation (Kapitalgesellschaft) & 0.490 & 0.500 & 0 & 1 \\
\hline Other legal form & 0.210 & 0.407 & 0 & 1 \\
\hline $\begin{array}{l}\text { Missing value for total wages and salaries } \\
\text { (dummy) }\end{array}$ & 0.130 & 0.337 & 0 & 1 \\
\hline Missing value for total investments (dummy) & 0.035 & 0.184 & 0 & 1 \\
\hline $\begin{array}{l}\text { Different unit surveyed in previous year } \\
\text { (dummy) }\end{array}$ & 0.038 & 0.191 & 0 & 1 \\
\hline $\begin{array}{l}\text { Already refused to take part in panel in the past } \\
\text { (dummy) }\end{array}$ & 0.053 & 0.224 & 0 & 1 \\
\hline Duration of participation in years & 5.009 & 3.382 & 1 & 13 \\
\hline Different unit surveyed (dummy) & 0.011 & 0.103 & 0 & 1 \\
\hline $\begin{array}{l}\text { Development of employment (reference: no } \\
\text { change) }\end{array}$ & 0.323 & 0.468 & 0 & 1 \\
\hline Increase in employment & 0.301 & 0.459 & 0 & 1 \\
\hline Reduction of employment & 0.376 & 0.484 & 0 & 1 \\
\hline $\begin{array}{l}\text { Questionnaire completed partly or entirely by } \\
\text { establishment itself (dummy) }\end{array}$ & 0.188 & 0.391 & 0 & 1 \\
\hline $\begin{array}{l}\text { Interviewer's education level (1= lower secon- } \\
\text { dary school leaving certificate, } 5=\text { =university } \\
\text { degree) }\end{array}$ & 3.129 & 1.507 & 1 & 5 \\
\hline $\begin{array}{l}\text { No. of years that interviewer has belonged to } \\
\text { interviewer team }\end{array}$ & 14.103 & 9.223 & 0 & 53 \\
\hline Interviewer's age & 61.959 & 10.401 & 27 & 90 \\
\hline Interviewer's sex male (dummy) & 0.382 & 0.486 & 0 & 1 \\
\hline Change of interviewer (dummy) & 0.075 & 0.264 & 0 & 1 \\
\hline No. of interviews in the wave (log) & 4.180 & 0.813 & 0 & 5.97 \\
\hline Establishment in eastern Germany (dummy) & 0.388 & 0.487 & 0 & 1 \\
\hline Establishment size (reference: 1-4 employees) & 0.193 & 0.193 & 0 & 1 \\
\hline 5-9 employees & 0.146 & 0.353 & 0 & 1 \\
\hline 10-19 employees & 0.122 & 0.328 & 0 & 1 \\
\hline 20-49 employees & 0.155 & 0.362 & 0 & 1 \\
\hline 50-99 employees & 0.107 & 0.309 & 0 & 1 \\
\hline 100-199 employees & 0.093 & 0.290 & 0 & 1 \\
\hline
\end{tabular}




\begin{tabular}{|l|r|r|r|r|}
\hline Name & $\begin{array}{r}\text { Mean } \\
\text { value }\end{array}$ & $\begin{array}{r}\text { Standard } \\
\text { deviation }\end{array}$ & $\begin{array}{r}\text { Minimum } \\
\text { Maximum }\end{array}$ \\
\hline $200-499$ employees & 0.103 & 0.304 & 0 & 1 \\
\hline $500-999$ employees & 0.044 & 0.206 & 0 & 1 \\
\hline $1000-4999$ employees & 0.033 & 0.180 & 0 & 1 \\
\hline $5000+$ employees & 0.004 & 0.060 & 0 & 1 \\
\hline Sectors (reference: agriculture/hunting/forestry) & 0.024 & 0.153 & 0 & 1 \\
\hline Mining/energy & 0.018 & 0.134 & 0 & 1 \\
\hline Food products/tobacco products & 0.027 & 0.162 & 0 & 1 \\
\hline Consumer goods & 0.032 & 0.177 & 0 & 1 \\
\hline Producer goods & 0.082 & 0.274 & 0 & 1 \\
\hline Capital goods / consumer durables & 0.115 & 0.318 & 0 & 1 \\
\hline Construction & 0.080 & 0.272 & 0 & 1 \\
\hline Wholesale and retail trade / repairs & 0.135 & 0.342 & 0 & 1 \\
\hline Transport / communication & 0.038 & 0.191 & 0 & 1 \\
\hline Financial intermediation & 0.030 & 0.170 & 0 & 1 \\
\hline Hotels and restaurants & 0.036 & 0.186 & 0 & 1 \\
\hline Education & 0.038 & 0.191 & 0 & 1 \\
\hline Health and social work & 0.093 & 0.290 & 0 & 1 \\
\hline Business services & 0.121 & 0.326 & 0 & 1 \\
\hline Other service activities & 0.042 & 0.202 & 0 & 1 \\
\hline Non-profit organisations & 0.024 & 0.154 & 0 & 1 \\
\hline Public administration & 0.065 & 0.246 & 0 & 1 \\
\hline N & 14902 & & & \\
\hline
\end{tabular}


FDZMethodenreport

No. $7 / 2009$

\section{Publisher}

The Research Data Centre (FDZ)

of the Federal Employment Service

in the Institute for Employment Research

Regensburger Str. 104

D-90478 Nuremberg

\section{Editorial staff}

Stefan Bender, Dagmar Herrlinger

Technical production

Dagmar Herrlinger

\section{Copyright}

Reproduction - also in parts - only with permission of the FDZ

\section{Download}

http://doku.iab.de/fdz/reporte/2009/MR 07-09.pdf

Internet

http://fdz.iab.de/

\section{Corresponding author}

Florian Janik, Institute for Employment Research, Regensburger Str. 104, D-90478 Nuremberg

Phone: +49-(0)911/179- 3830

E-Mail: Florian.Janik@iab.de 